\title{
Türkiye Ekonomisinde Büyümenin Sektörel Belirleyicileri: İller Düzeyinde 2004-2014 Y1lları Arasında Ampirik Bir İnceleme
}

\author{
Ömer Tuğsal Doruka, b
}

Özet

Türkiye ekonomisinde iller düzeyinde büyümenin sektörel belirleyicileri, bu çalışmada statik ve dinamik panel veri analizi vasıtasıyla 2004-2015 yılları arasında araştırılmaktadır. Elde edilen sonuçlar büyümenin önemli düzeyde hizmetler sektörü tarafından yönlendirildiğini, sanayi sektörünün büyümeye olan katkısının hizmetler sektörünü takip ettiğini göstermektedir. Tarım sektörünün büyümeye olan katkısı istatistiksel olarak anlamlı bulunmasına karşın diğer iki sektöre göreli olarak en az düzeydedir.
Anahtar Kelimeler

Ekonomik büyüme

Bölgesel büyüme

Büyümenin sektörel belirleyicileri

Makale Hakkında

Geliş Tarihi: 30.10 .2018

Kabul Tarihi: 24.04 .2020

Doi: 10.18026/cbayarsos.476582

\section{Sectoral Determinants of Growth in The Turkish Economy: An Empirical Analysis in the City-Level between 2004 and 2014}

\footnotetext{
Abstract

By using static and dynamic panel data analyses, the sectoral determinants of economic growth in city-level are examined in the period 2004-2015. The obtained findings show that economic growth is managed by the services sector, and the manufacturing sector follows this sector. The contribution of the agricultural sector to economic growth is the least contribution to growth, while so do services sector is high.
}

Keywords

Economic growth Regional development

Sectoral determinants of economic growth

About Article

Received: 30.10 .2018

Accepted: 24.04 .2020

Doi: 10.18026/cbayarsos.476582

a İletişim Yazarı: otdoruk@atu.edu.tr

b Dr. Öğretim Üyesi, İşletme Fakültesi, Adana Alparslan Türkeş Bilim ve Teknoloji Üniversitesi, e-mail: otdoruk@atu.edu.tr, ORCID: 0000-00022382-1042 


\section{Giriş}

Sektörel değişimlerin ekonomik büyüme üzerine olan etkisi iktisat literatüründe oldukça tartışmalı bir konumdadır. Tarım ile ekonomik büyüme arasındaki ilişkinin artık yetersiz olduğu ve tarımsal verimliliğin ölçeğe göre azalan getiriye sahip olduğunu savunan iktisat politikaları beraberinde sanayileşme-ekonomik büyüme ilişkisini destekleyici varsayımları ve teorileri getirmiştir.

Tarımdan sanayiye geçişi sanayileşme yoluyla ekonomik büyümenin önemli bir faktörü olarak gösteren çalışmalar arasında Kaldor (1966), Rosenstein-Rodan (1943), Nurkse (1953), Lewis (1954), Hirschman (1958), Myrdal (1957), Chenery (1960; 1979) bulunmaktadir. Bu çalışmalarda uzun vadeli ekonomik büyümenin ve sanayileşmenin ekonomideki yapısal dönüşüm üzerine olan olumlu etkisi vurgulanmaktadır. Tarım sektörünün gelişmesinin talep ile paralel olarak çıktı düzeyini arttıracağı varsayımına karşın tarım ürünlerine olan talebin sınırlı olması nedeniyle sektörel düzeyde büyüme ve dolayısıyla tarım sektörünün ekonomik büyümeyi sınırlandıracağı yönünde bir öngörü bulunmaktadır. Nitekim az gelişmiş ülkelerin tarım sektörünün GSYİH'ya oranı, dünya ortalamasının oldukça üzerinde yer almaktadır (Dünya Bankası, 2018).

Kuznets (1966) uzun vadeli büyüme ve kalkınma için tarımdan sanayiye olan yapısal dönüşümün kaçınılmaz olduğunu belirtmektedir. Chenery vd. (1986) ekonomide yaşanan bu yapısal dönüşümün temelinde 'Hollanda Hastalığı' nın yattığını belirtmektedir. Tarımsal ürüne dayalı üretim yapan ve bu ürünlere dayalı ihracat stratejisine sahip olan ülkeler dış ticaret hadlerindeki önemli düzeyde bozulmalar ile birlikte büyümeyi ve dolayısıyla kalkınmayı sürdürülebilir kılan bir yapıya sahip değildir. Sanayileşmenin önemli düzeyde yapısal dönüşüm vasıtasıyla sermaye birikimine, üretkenliğe, teknik ilerlemeye olan katkısına ve dış ticaret hadlerine tarıma göreli olarak önemli düzeydeki etkisi sanayileşmeyi hızlandıran etkenler arasında yer almaktadır.

Sanayileşmenin ekonomik büyüme üzerine olan etkisinin önemli dönüşümleri beraberinde getirmesi ve ekonomik büyümeyi hızlandırmasını savunan görüşün yanı sıra büyüme iktisadında son çalışmalar (Szirmai ve Verspagen, 2011; Fagerberg ve Verspagen, 1999; Szirmai, 2012) imalat sanayideki gelişmelerin yanı sıra sanayileşmeden hizmetler sektörüne olan önemli kaymaların mevcut olduğunu belirtmektedir. Son dönemdeki bu hızlı geçiş, hizmetler sektörüne olan geçişin açılanması Rowthorn (1995)'in ters U eğrisine göre yorumlanmaktadır. Rowthorn (1995)'un ters U eğrisi yaklaşımında sanayileşmenin önemli düzeyde kişi başına milli geliri arttırarak orta gelir düzeyine gelene kadar büyümeyi ve kalkınmayı desteklediğini, ancak daha sonra hızlı bir şekilde beraberinde sanayisizleşmeyi (de-industrialization) getirdiği varsayımı yapılmaktadır. Ancak sanayisizleşme çoğunlukla gelişmiş ya da sanayileşmesini tamamlamış ülkelerde görülen bir yapıdadır. Bu noktada sanayiden hizmetler sektörüne olan hizlı geçiş Rowthorn ve Coutts (2004), Palma (2005), Pieper (2003), Rowthorn ve Wells, (1987)'e göre gelişmiş ülkelerden çok daha düşük bir noktada gerçekleşmektedir. Bu geçişin en önemli özellikleri olarak sanayileşmedeki başarısızlıklar ve hizmetler sektörünün küresel ölçekte gelişmesi görülmektedir (Rowthorn ve Wells, 1987). Kefela (2010:126)'ya göre hizmetler sektörü, 1990 ile 2010 yılları arasında düşük ve orta gelirli ülkeler için GSYİH'dan daha hızlı bir gelişme göstermiştir. Hizmete dayalı büyümeyi ülke politikası olarak uygulayan ve dünya çapında başarılı bir örnek olarak Hindistan verilebilir. Nitekim Hindistan hizmetler sektörünün büyümesi sonucunda ülke kalkınmasını hedeflenmektedir. Hizmetler sektörüne yönelik büyüme politikaları gelişmiş 
ülkelerde belirli sistematik aşamaların sonucunda oluşmuş olsa da küresel düzeyde artan rekabet, hizmetler sektörünün az maliyetli olması hizmetler sektörüne olan talebin büyümesi, sermaye birikiminin istenilen düzeyde olmaması gibi faktörler, gelişmekte olan ülkelerin hizmetler sektörüne olan ilgisini arttırmıştır. 1990 yılı ve sonrasında küreselleşmenin de etkisiyle gelişmekte olan ülkelerin gelişmiş ülkelerdeki tüketim kalıplarını taklit etmesi de gelişmekte olan ülkelerde hizmetler sektörünün gelişmesine olanak tanıyan diğer bir nedendir. Soubbotina, (2004: 66)'ya göre dünya genelinde hizmetler sektörünün önemli bir paya sahip olduğu ve iktisadi sektörler içerisinde dünya genelinde etkin bir sektör olduğu yorumlanabilir.

Çalışmanın ana hipotezi olarak hizmetler sektörünün ekonomik büyümeye olan katkısının sanayi ve hizmetler sektöründen fazla olmasıdır. Çalışmada 2004 yılı ile 2014 yılları arasında Türkiye' de İBBS 3.Düzey 81 il kullanılarak il düzeyinde heterojen ve oldukça zengin bir veri setinin kullanılması ile birlikte ekonomik büyümenin sektörel belirleyicileri test edilmektedir. Çalışmada panel veri analizi kullanılarak tarım, sanayi ve hizmetler sektörünün büyümeye olan etkisi analiz edilmektedir.

Çalışmada elde edilen sonuçlar Türkiye ekonomisinde ekonomik büyümeye olan katkının hizmetler, sanayi ve tarım sektörü olarak sıralandığını göstermektedir. Çalışmanın ikinci bölümünde genel olarak hizmetler sektörü ve gelişimi açıklanmaktadır. Üçüncü bölümde veri seti, metodoloji, hipotez ve ekonometrik bulgular yer almaktadır. Son bölümde ise genel sonuçlar, öneriler ve kisıtlar yer almaktadır.

\section{Türkiye Ekonomisinde Sektörel Geçişler: 1950 Sonrası Dönem}

1950-1959 yılları arasındaki dönemde tarım sektörüne dayalı büyüme politikaları beraberinde tarım teşvik ve sübvansiyonlarını getirmiştir. Türkiye ekonomisinde 1950'li yılların son döneminden itibaren 1960'lı yılların ilk yarısından itibaren planlı büyüme politikaları arasında 'bebek sanayi tezi' ne dayalı olarak ithal ikameci sanayileşme politikası uygulanmaya başlanmıştır. Bu dönemden itibaren 1960 ile 1980 yılları arasında uygulanan ithal ikameci yaklaşımın uygulanmasında oldukça istikrarsız dönemler art arda gelmiştir. 1960 yılında uygulanmaya konulan ithal ikameci dönemde IMF ile imzalanan stand-by anlaşmalarının da etkisiyle sanayi sektörüne ağırlık verilmiştir. Ancak bu dönemde yaşanan ekonomik ve politik istikrarsızlıklar beraberinde istikrarsız sermaye birikimi sürecini getirmiştir (Öniş, 2010). Sanayi sektöründe bu dönemde sanayi politikalarının da sanayi üretimini destekleyecek noktada olmaması da sanayi sektöründe üretimi destekleyememiş ve ithalat bağımlılığına olan ihtiyacın azaltılamamasına neden olmuştur (Doruk, 2017).

1978 Krizi'ni takip eden süreçte 1980 ile 1989 dönemi arasında ihracata dayalı büyüme politikaları ile birlikte sanayi üretiminde önemli artışlar yakalanmıştır. Bu ilerlemenin ardında ihracata yönelik teşviklerin nakit ve önemli düzeyde ihracat harcamalarını karşılamasında yatmaktadır (Atiyas ve Bakış, 2015). Ancak Türkiye'nin Gümrük Birliği'ne üyelik aşaması beraberinde Dünya Ticaret Örgütü (DTÖ) ve Avrupa Birliği (AB)'nin bölgesel genişleme politikaları ile bu nakit destekler 1980'li yılların sonunda önemli düzeyde azaltılmış ve Gümrük Birliği üyeliği sonrasında bölgesel desteklere dönmüştür (Atiyas ve Bakış, 2015; Eser, 2011).

1980 sonrası dönemde sanayideki çıktı oranı, tarımdaki çıktı oranındaki azalma ve kademeli olarak sanayi sektörüne yönelen Türkiye, büyümenin motoru olarak sanayiyi, ülke ekonomisinin merkezine oturtmuştur. Türkiye' de 1980 sonrası yapısal dönüşüm sonrasında 
sanayileşme, ön plana çıkarılmış ve sanayiye ağırlık verilmiştir. 1989 sonrası dönem 1989 yılında 32 Sayılı Kararname ile finansal hesapların liberalizasyonu ile finansal serbestleşme dönemine geçen Türkiye ekonomisi daha dışa açık bir ekonomi görünümüne kavuşmuştur. Hizmetler sektöründe önemli bir payı olan bankacılık sektörünün gelişmesine paralel olarak 1990'lı yılların başından itibaren hizmetler sektörü önemli bir gelişme ivmesine sahip olmuştur. Hizmetler sektörü, 1990 sonrasında dünya genelinde ciddi düzeyde yükselen bir ivme yakalamıştır. 1990 sonrasında finansal ve mali kuruluşların ülke ve dünya ekonomisinde önemli bir yer tutması ve Washington Konsensüsü, Dünya Ticaret Örgütü'nün ticaretin serbestleştirilmesine yönelik politikaları, Uruguay Raundu gibi ticaretin serbestleşmesine yönelik politikaların izlenmesi hizmetler sektörünün dünya genelinde önemli bir yer tutmasında etkin rol oynamıştır.

Sanayiden hizmetler sektörüne geçiş bu gelişmelerin yanı sıra Rowthorn ve Wells (1987) tarafından da belirtildiği üzere gelişmekte olan ülkelerin kronik sorunlarından birisi olan sermaye birikiminin yavaşlaması sorunsalı, Türkiye'de sanayi sektörüne nazaran daha az maliyete ihtiyaç duyan hizmetler sektörünün büyümesine neden olmuştur. Türkiye ekonomisinde sektörel kaymalar, net bir şekilde sektörel istihdam oranlarında görülebilmektedir. 1990 yılında çoğunlukla tarım sektöründe görülmektedir. 2017 yılındaki verilere göre tarım sektöründeki istihdam kaymalarının sanayi sektöründen daha fazla hizmetler sektörüne doğru olduğu görülmektedir. Bu noktada nüfusun artışının da etkisiyle istihdam edilen kişi sayısında artışa neden olduğu ancak bu artıştan da önemli bir payın hizmetler sektörüne doğru yöneldiği görülmektedir. Tablo 1'de bu istihdam kaymasına dair veriler yer almaktadır.

Tablo 1. Sektörler itibariyle istihdam (15+ yaş, bin kişi)

\begin{tabular}{|l|l|l|}
\hline Sektör & $\mathbf{1 9 9 0}$ & $\mathbf{2 0 1 7}$ \\
\hline Tarım & 8,444 & 5,464 \\
\hline Sanayi & 2,845 & 5,383 \\
\hline Hizmetler & 6,874 & 15,247 \\
\hline
\end{tabular}

Kaynak: Strateji ve Bütçe Başkanlığı,2018, Ekonomik ve Sosyal Göstergeler

Şekil 1'de tarım, sanayi ve hizmetler sektörlerinin 1923 ile 2017 yılları arasında büyüme oranları yer almaktadır. 1923 ile 1950'li yılların sonuna kadar tarım sektörünün önemli büyüme oranlarına sahip olduğu görülmektedir. Ancak ithal ikameci yaklaşım politikalarının etkisiyle 1960-1980 yılları arasında sanayi sektörünün büyüme oranı artmış, tarım sektörünün büyüme oranı azalma eğilimi içerisinde olmuştur. Ancak 1990 yılı sonrasında hizmetler sektöründe önemli büyüme hızlarına ulaşıldığı görülmektedir. 2000'li yıllarda ise 2001 ve 2008 finansal kriz dönemleri hariç hizmetler sektöründe istikrarlı bir büyüme artışının yakalandığı görülmektedir. 


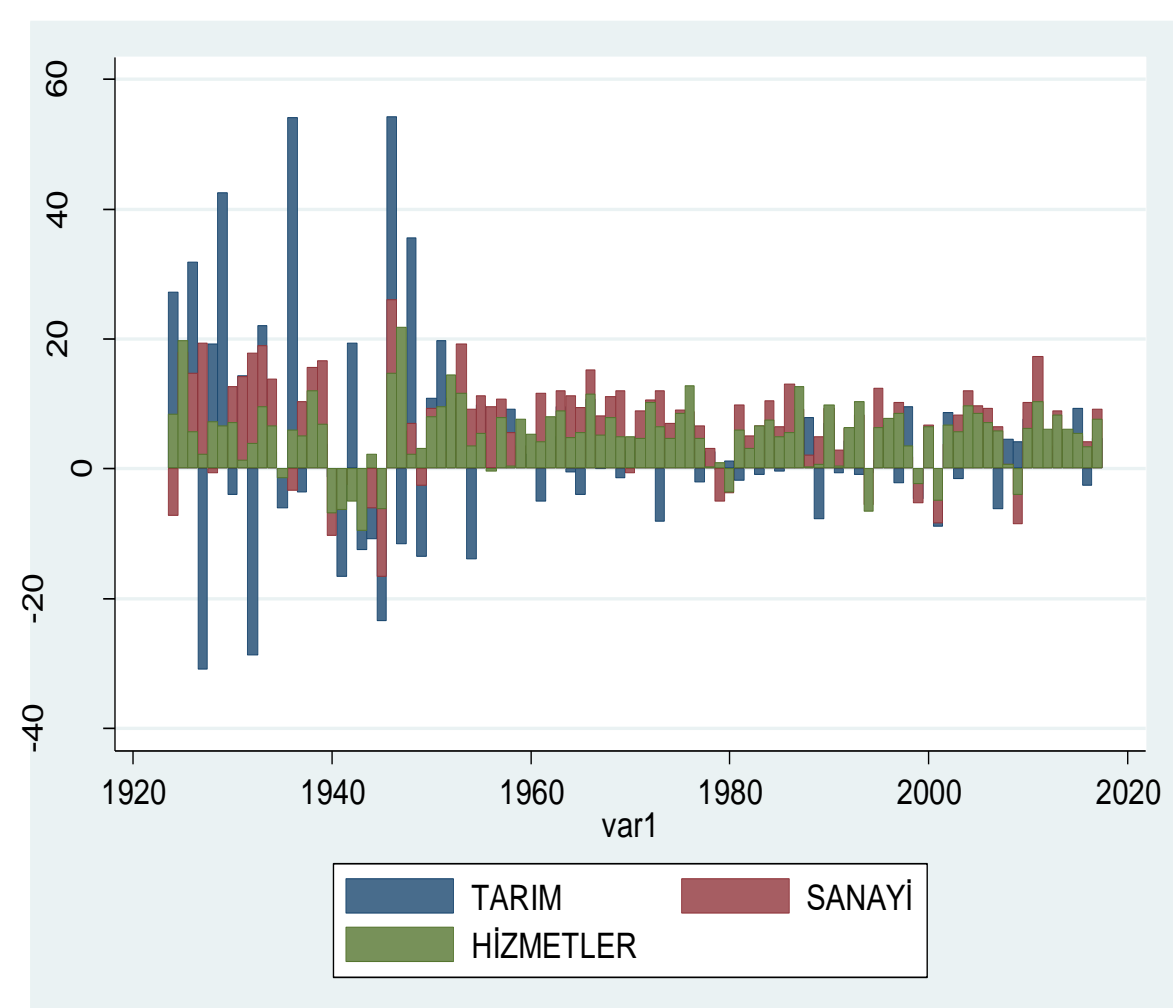

Kaynak: : Strateji ve Bütçe Başkanlığı,2018, Ekonomik ve Sosyal Göstergeler

Şekil 1. Türkiye' de Sanayi, Tarım ve Hizmetler Sektörü Büyümesi, 1923-2017, \%

Şekil 1'de görülen bir diğer önemli nokta ise; 1960 sonrası dönemde sektörel büyüme oranlarının önceki dönemlere göre daha az olmasıdır. Bu durumun sektörel büyümenin 19231960 döneminde oldukça hızlı olarak yeni kurulan bir ekonomide/ülkede olgunlaşma dönemini ifade ettiği yorumlanabilir.

Şekil 2'de tarım, sanayi ve hizmetler sektörlerinin dünya genelinde 1997 ile 2010 yılları arasındaki gelişimi görülmektedir. Türkiye ekonomisinde tarım sektörünün GSYİH içerisindeki katma değerinin OECD ve Dünya ortalamasının üzerinde olduğu görülmektedir. Sanayi sektörünün katma değerinin GSYİH'ya oranının dünya ve OECD ortalamasının dönem dönem üzerinde olduğu görülmektedir. Genel itibariyle sanayinin katma değerinin GSYİH'ya oranının dünya ve OECD ortalamasında seyrettiği görülmektedir. Hizmetler sektörünün katma değerinin GSYİH'ya oranının dünya ve OECD ortalamasının oldukça gerisinde olduğu görülmektedir. 


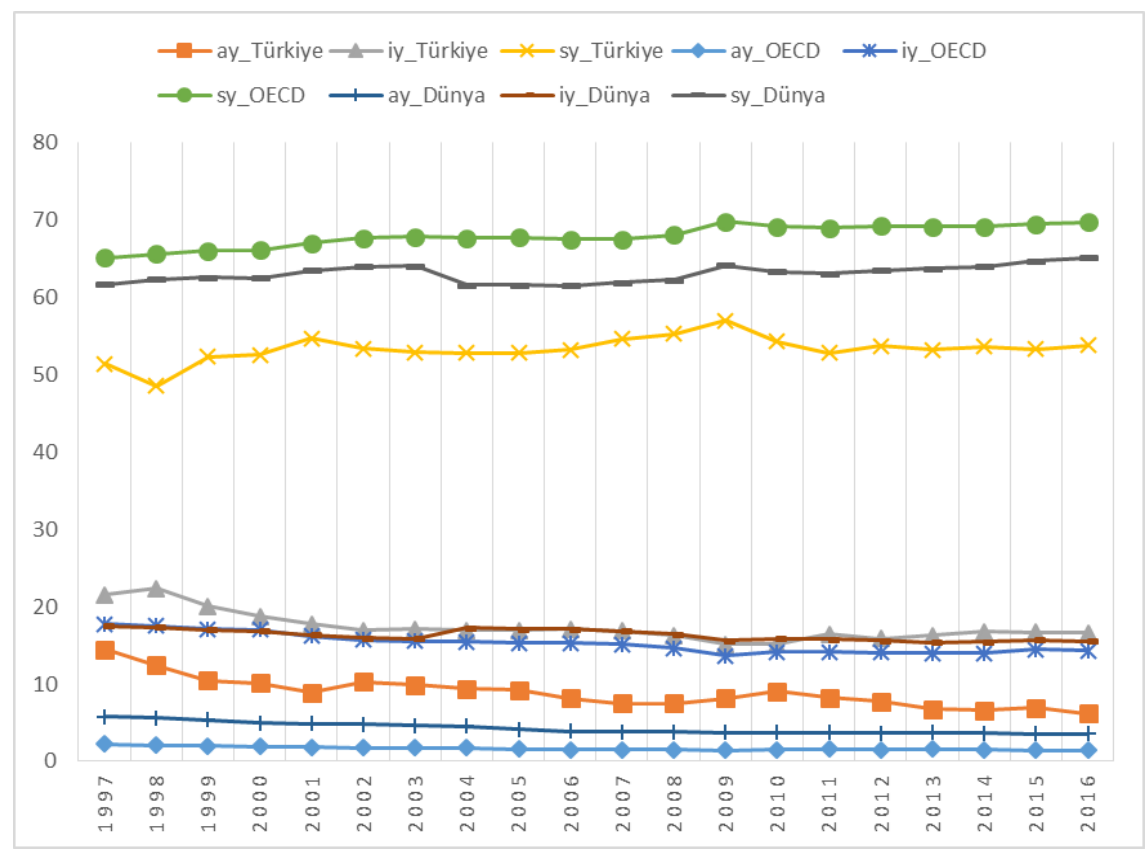

Not: ay; iy; sy sırasıyla tarım sektörünün GSYİH içerisindeki payını, sanayi sektörünün GSYİH içerisindeki payını ve hizmetler sektörünün GSYİH içerisindeki payını ifade etmektedir. Verilerde 1997 yılından önceki ve 2017 yılından sonraki dönemde eksiklikler bulunması nedeniyle zaman aralığı 19972016 yılı olarak seçilmiştir.

Kaynak: Dünya Bankası,2018

Şekil 2.Tarım, Sanayi ve Hizmetler Sektörlerinin Seçilmiş Gruplar İçin Katma Değeri (GSYİH'nın \%'si)

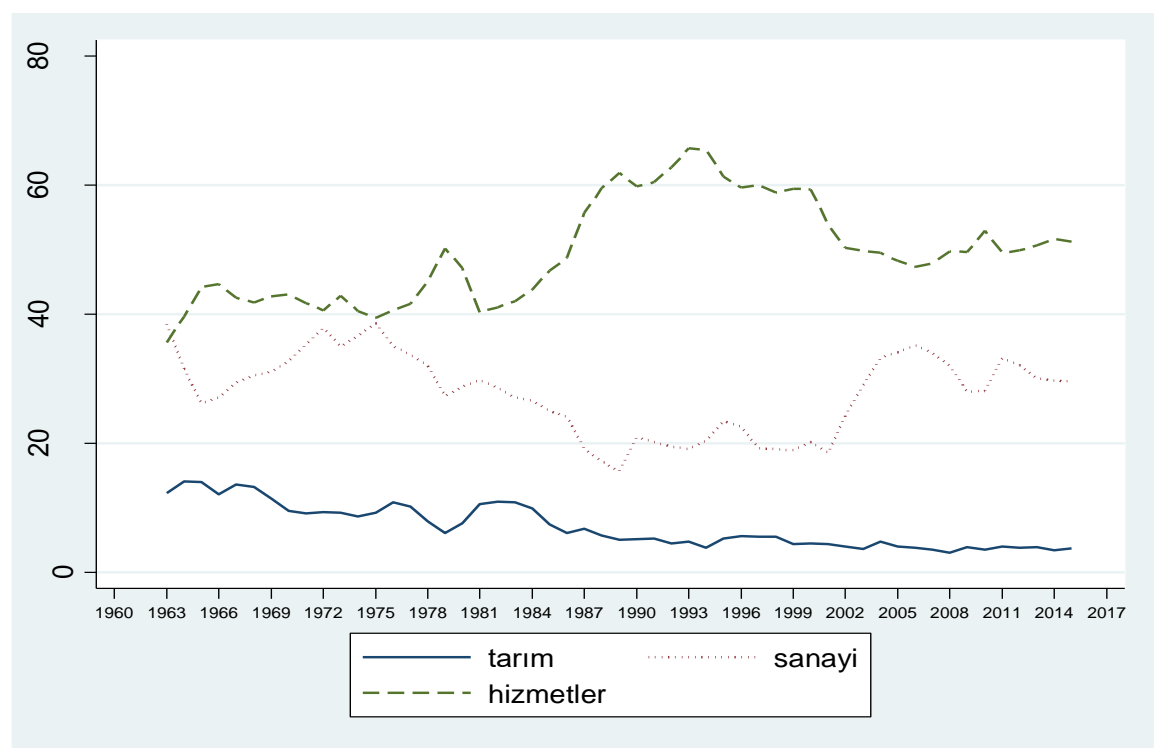

Not: Hizmetler değişkeni, Ulaştırma, Turizm, Konut, Eğitim, Sağlık ve Diğer Hizmetler sektörleri toplanarak elde edilmiştir.

Kaynak: : Strateji ve Bütçe Başkanlığı,2018, Ekonomik ve Sosyal Göstergeler

Şekil 3. Sabit Sermaye Yatırımlarının GSYİH içerisindeki payının Tarım, Sanayi ve Hizmetler sektörleri özelinde dağılımı, 1963-2017 
Şekil 3'te sabit sermaye yatırımlarının GSYİH içerisindeki payının tarım, sanayi ve hizmetler sektörü özelinde 1963 ile 2017 yılları arasındaki gelişimi yer almaktadır. Sanayi sektöründeki sabit sermaye yatırımlarının özellikle 1990 sonrasında \%18 ile \%35 arasında kaldığ1 görülmektedir. Tarım sektöründeki sabit sermaye yatırımlarının ise 1980'li yılların son döneminden itibaren önemli düzeyde azaldığı görülmektedir. Buna karşın hizmetler sektöründeki sabit sermaye yatırımlarının özellikle 1980'li yılların başından itibaren önemli düzeyde bir artışa sahip olduğu görülmektedir.

\section{Ekonometrik Analiz Ve Metodoloji}

\section{Veri Seti}

Çalışmada kullanılan veri seti TÜİK (2018) Bölgesel İstatistikler veri tabanından elde edilmiştir. Ekonometrik analiz için kullanılan veri setinde 2004 ile 2014 yılları arasında 81 ile ait gözlemler yer almaktadır. Analizde kullanılan değişkenlerin tümü Dünya Bankası (2018) Dünya Kalkınma İstatistikleri (2018)'den elde edilen ve 2004=100 olarak tekrar endekslenen GSYİH deflatörü ile enflasyon etkisinden arındırılarak reelleştirilmiştir. Çalışmada kullanılan veri seti 81 ile ait 11 dönemi içeren toplam 891 gözleme sahiptir. Analize değişkenlerin logaritmaları alınarak logaritmik serileri ile başlanmıştır. Ancak karşılaşılan çoklu doğrusal bağlantı sorunu ve panel veri analizinde GMM modellerindeki teşhis testlerindeki tutarsızlık nedeniyle tüm değişkenler büyüme oranı haline çevrilmiştir. Veri setinde yer alan değişkenlerin büyüme oranlarının hesaplanması amacıyla birinci farklarının alınması nedeniyle 2005-2014 yılları arasında 81 ile ait veriler ile 810 gözleme sahiptir.

Panel veri analizi kısa zaman aralığında daha fazla farklı serinin bir arada kullanılmasına olanak tanımakta ve analizi zenginleştirmektedir. Baltagi (2005:5)'ye göre panel veri analizi diğer analizlere oranla daha etkin, daha ölçülebilir ve daha fazla serbestlik derecesine sahip olarak araştırmaya katkı sağlamaktadır.

Çalışmanın dayandığı ana fonksiyon eşitlik 1'deki gibidir.

$$
g Y=f\left(g_{a}, g_{i}, g_{s}\right)
$$

Bu eşitlikte Y; GSYİH'yı, a,i ve s alt indisleri sırasıyla tarım, sanayi ve hizmetler sektörünü ifade ederken değişkenlerin önünde yer alan g ön eki büyümeyi ifade etmektedir. Eşitlik 1'de yer alan fonksiyonu, ekonometrik model olarak eşitlik 2' deki gibi ifade edebiliriz.

$$
g Y_{i, t}=\beta_{0}+\beta_{1} g_{a_{i, t}}+\beta_{2} g_{i_{i, t}}+\beta_{3} g_{s_{i, t}}+a_{i, t}+\varepsilon_{i, t}
$$

Eşitlik 2'de yer alan ifadelerde sabit etkiler modelinde yer alan illere göre sabit etkileri göstermektedir. Sabit etkiler modeli, analizde yer alan her birim için bir sabit katsayıya sahip olarak modeli tahmin etmektedir. Bu modelin en önemli kullanılma gerekçelerinden birisi hata terimi ile değişkenler arasındaki ilişkinin mevcut olmasıdır. Diğer bir model olan rastsal etkiler modelinde değişkeninin zamana ve birimlere göre değişmediği varsayılmaktadır. Rastsal etkiler modelinde hata terimi ile değişkenler arasında bir ilişkinin mevcut olmadığ varsayımı yapılmaktadır .

Klasik statik panel veri analizi modellerinin yanı sıra son dönemde özellikle finans ve iktisat literatüründe sıkça kullanılan Genelleştirilmiş Momentler Metodu (GMM) yöntemi bu çalışmada kullanılan ve Eşitlik 1'i test etmek için kullanılan ana modeldir. Özellikle tarım, 
sanayi ve hizmetler sektörünün büyümeyi destekleyeceği gibi vice versa bir ilişkinin de mevcudiyetinin modellenmesi açısından tercih edilmiştir. Diğer bir deyişle analizde kullanılan değişkenlerin potansiyel içsel değişken olması durumu GMM'in seçilmesinin ana nedenlerinden birisidir. Örneğin sanayiden büyümeye bir ilişkinin olmasının yanı sıra büyümenin de sanayiyi desteklemesi söz konusu olabilir. Aynı zamanda büyüme iktisadında sıkça söz edilen 'patika bağımlılığı' etkisini test etmek amacıyla GSYİH büyümesinin bir dönem önceki değeri de ekonometrik modele eklenerek dinamik bir analiz yapılması hedeflenmektedir. Ancak bağımlı değişkenin bir dönem önceki değerinin eşitliğin sağ tarafına bağımsız değişken olarak eklenmesi, modelde hata terimi ile bağımlı değişken arasındaki ilişkiyi ifade eden içsellik (endogeneity) sorununa neden olmaktadır. GMM'in bu noktada oldukça etkin bir tahminci olması, ekonometrik analiz için seçilmesinin diğer bir nedenidir. GMM'in seçilmesinin diğer bir nedeni olarak birimler arası birinci dereceden otokorelasyon ve değişen varyans sorununa karşı etkin tahminler sağlamasıdır (Arellano ve Bond, 1991). GMM modelinde aynı zamanda zamana karşı gözlemlenemeyen etkilerin kontrolü için yıllara göre yıl kukla değişkenleri kullanılmaktadır.

GMM modelinin tahmin edilmesinde Fark-GMM modeli iller arasında teknolojik farklılıkların ortadan kaldırılması açısından değişkenlerin birinci farkını alarak bu farklılıkları minimuma indirgemesiyle avantajlı olmasından dolayı tercih edilmiştir. Nihai olarak tahmin edilen FarkGMM eşitlik 3'te yer aldığ ş̧ekildedir.

$$
g Y_{i, t}=\beta_{0}+\beta_{1} g_{a_{i, t}}+\beta_{2} g_{i_{i, t}}+\beta_{3} g_{s_{i, t}}+\beta_{4} g_{y_{i, t-1}}+\varepsilon_{i, t}
$$

Eşitlik 3'te yer alan sabit terim fark alınması nedeniyle modelden daha sonra çıkarılmaktadır.

GMM modelinin tutarlılığını test etmek amacıyla Hansen J Testi, Wald Test, AR(1) ve AR(2) teşhis testleri kullanılmaktadır. Bu teşhis testlerinden Hansen J Testi, modelde kullanılan araç değişkenlerden kaynaklı aşırı tanımlama (over-identification) sorununun varlığını test etmek amacıyla kullanılmaktadır. Hansen J Testi'nde yokluk hipotezinin \%5 istatistiksel anlam düzeyinde kabul edilmemesi modelde aşırı tanımlama hatasının olmadığını belirmektedir. Tahmin edilen GMM modelinde otokorelasyon testinin fark alınmış hata terimlerinde birinci mertebeden otokorelasyonu test eden $\mathrm{AR}(1)$ ve bu hata terimlerinde ikinci mertebeden otokorelasyonu test eden $\mathrm{AR}(2)$ testleri modelde otokorelasyonu test etmektedir. $\mathrm{AR}(1)$ testinde otokorelasyonun varlığ beklenen bir durum iken AR(2) testinde t-2 ve sonrası düzeyinde modellenen araç değişkenlerin geçerli araç değişkenler olması açısından otokorelasyonun olmaması beklenmektedir. Wald Testi ise tahmin edilen modelin bir bütün olarak anlamlılı̆̆ını test etmektedir.

\section{Çalışmanın Hipotezi}

Türkiye ekonomisinde sanayi sektörünün istenilen sermaye birikimini sağlayamaması, ithalata olan bağımlılık, gelişmiş ülke ekonomilerindeki tüketim kalıplarının taklit edilmesi ve küresel ölçekte hizmetler sektörünün önemli gelişmeler göstermesi gibi önemli faktörler hizmetler sektörünün gelişmesine olanak tanıyan faktörler olmuşlardır. Hizmetler sektörünün gelişimi Rowthorn (1995)'un ters U eğrisini destekler nitelikte sanayide beklenilen çıkışın istenilen düzeyde olmamasından kaynaklı olarak hizmetler sektörüne geçişi sağlamıştır. Dolayısıyla çalışmanın ana hipotezi hizmetler sektörünün bu gerekçeler ışığında büyümeye önemli düzeyde katkıda bulunmasıdır. 


\section{Bulgular}

Çalışmada kullanılan tüm değişkenlere ait açıklayıcı istatistikler Tablo 2' de yer almaktadır. Örneklemin ortalama büyüme oranı $\% 5$, hizmetler sektörünün ortalama büyüme oranı $\% 5.4$, sanayinin ortalama büyüme oranı $\% 8.1$ ve tarım sektörünün ortalama büyüme oranı $\% 1.5$ 'tur. Örneklemde en fazla standart sapma tarım sektörünün büyüme oranında yer alırken, en az standart sapma sanayi sektörünün büyüme oranında yer almaktadır. Örneklem toplam 810 gözlemden oluşmaktadır ve dengeli panel veri seti olma özelliğindedir.

Tablo 2. Açıklayıcı İstatistikler

\begin{tabular}{|c|c|c|c|c|c|}
\hline Değişken & Ortalama & $\begin{array}{l}\text { Standart } \\
\text { Sapma }\end{array}$ & Min. & Maksimum & Gözlem sayısı \\
\hline gY & 0.051758 & 0.051572 & -0.11031 & 0.243395 & $\begin{array}{l}\mathrm{N}=810 \\
\mathrm{n}=81 \\
\mathrm{~T}=10\end{array}$ \\
\hline ga & 0.015736 & 0.143991 & -0.47154 & 0.635774 & $\begin{array}{l}\mathrm{N}=810 \\
\mathrm{n}=81 \\
\mathrm{~T}=10\end{array}$ \\
\hline gi & 0.081102 & 0.103204 & -0.33488 & 0.411085 & $\begin{array}{ll}\mathrm{N}= & 810 \\
\mathrm{n}= & 81 \\
\mathrm{~T}= & 10\end{array}$ \\
\hline gs & 0.054426 & 0.036495 & -0.0673 & 0.179389 & $\begin{array}{ll}\mathrm{N}= & 810 \\
\mathrm{n}= & 81 \\
\mathrm{~T}= & 10\end{array}$ \\
\hline
\end{tabular}

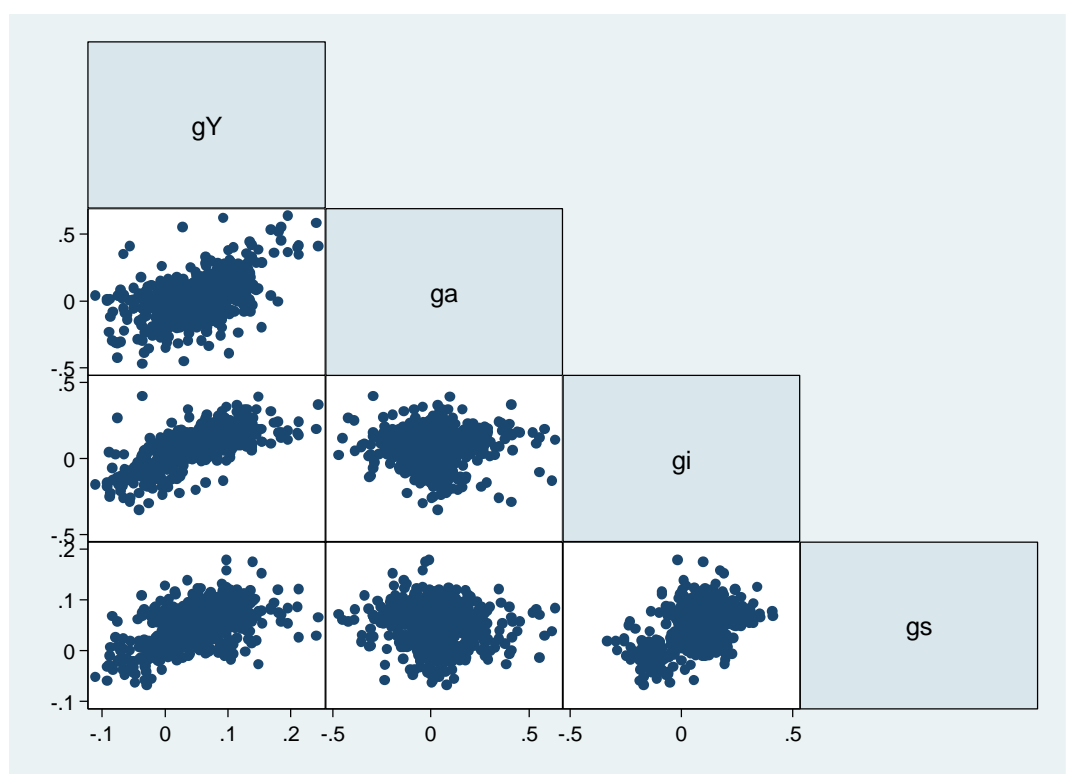

Kaynak: Yazar tarafından TÜİK (2018) verileri kullanılarak hesaplanmıştır.

Şekil 4. Değişkenler arasındaki İlişkiye İlişkin Serpilme Grafiği

Şekil 4'te değişkenler arasındaki korelasyon ilişkisine ait serpilme grafiği ve Tablo 2'de değişkenler arasındaki korelasyon ilişkisine ait korelasyon matrisi yer almaktadır. Şekil 4 ve 
Tablo 3’ye göre sanayi sektörü, hizmetler sektörü ve tarım sektörünün büyümeye olan etkisi olumludur. Tablo 3 ve Şekil 4 'te yer alan bir diğer önemli nokta ise çalışmanın bağımsız değişkenleri arasında çoklu doğrusal bağlılık (multicollinearity) sorununun bulunmamasıdır.

Tablo 3. Korelasyon Matrisi

\begin{tabular}{|l|l|l|l|l|}
\hline & gY & ga & gi & gs \\
\hline gY & 1 & & & \\
\hline ga & 0.5053 & 1 & & \\
\hline gi & 0.6977 & -0.0074 & 1 & \\
\hline gs & 0.5499 & -0.1411 & 0.4857 & 1 \\
\hline
\end{tabular}

Tablo 4. Rastsal etkiler ve Sabit Etkiler Modeline Dayalı Regresyon Sonuçları

\begin{tabular}{|c|c|c|}
\hline & $\begin{array}{l}(1) \\
\mathrm{gY} Y_{i, t} \\
\text { SE }\end{array}$ & $\begin{array}{l}(2) \\
\mathrm{gY}_{\mathrm{i}, \mathrm{t}} \\
\mathrm{RE}\end{array}$ \\
\hline ga, $\mathrm{t}$ & $\begin{array}{l}0.202^{* * *} \\
(14.27)\end{array}$ & $\begin{array}{l}0.201^{\text {**** }} \\
(14.24)\end{array}$ \\
\hline$g i_{i, t}$ & $\begin{array}{l}0.267^{* * * *} \\
(15.14)\end{array}$ & $\begin{array}{l}0.259^{* * * *} \\
(15.36)\end{array}$ \\
\hline $\mathrm{gSS}_{\mathrm{i}, \mathrm{t}}$ & $\begin{array}{l}0.513^{* *+} \\
(17.72)\end{array}$ & $\begin{array}{l}0.533^{\text {w*****4}} \\
(18.84)\end{array}$ \\
\hline$\beta_{0}$ & $\begin{array}{l}-0.000996 \\
(-0.77)\end{array}$ & $\begin{array}{l}-0.00145 \\
(-1.32)\end{array}$ \\
\hline$N$ & 810 & 810 \\
\hline$R^{2}$ & 0.86 & 0.86 \\
\hline$F$ istat. & 0.00 & 0.00 \\
\hline
\end{tabular}

Not: Ga, Gi, Gs sırasıyla tarım sektörünün GSYİH içerisindeki payının artışını, sanayi sektörünün GSYİH içerisindeki payının artışını ve hizmetler sektörünün GSYİH içerisindeki payının artışını ifade etmektedir. gY ise bağımlı değişken olan GSYİH artışını ifade etmektedir. Parantez içerisindeki değerler $\mathrm{t}$ istatistiklerini ifade etmektedir. ${ }^{*} \mathrm{p}<0.05,{ }^{* *} \mathrm{p}<0.01,{ }^{* * *} \mathrm{p}<0.001$

Tablo 4'te yer alan sonuçlara göre hizmetler sektörünün büyümeye olan katkısının sanayi ve tarım sektörlerinin büyümeye olan katkısından fazla olduğu görülmektedir. Sanayi sektörünün ekonomik büyümeye katkısı hizmetler sektörlerine göreli olarak az ancak tarım sektörüne göreli olarak fazla olduğu görülmektedir. Türkiye ekonomisinde tarım sektörünün önemini kaybetmesine parallel olarak büyümeye olan katkısının az olduğu görülmektedir. İki modelinde açıklama gücü \%86 düzeyindedir ve iki modelde istatistiki olarak anlamlıdır. İki modelde değişen varyans (heteroskedasticite) ve otokorelasyon sorunlarına karşıllk dirençli standart hatalar ile test edilmiştir. 
Tablo 5. Fark-GMM modeli sonuçları

\begin{tabular}{|c|c|}
\hline & $\begin{array}{c}(3) \\
\mathrm{gY}_{\mathrm{i}, \mathrm{t}}\end{array}$ \\
\hline gai,$t$ & $\begin{array}{l}0.184^{*+4+x} \\
(6.81)\end{array}$ \\
\hline$g i_{i, t}$ & $\begin{array}{l}0.246^{*+*+1} \\
(7.08)\end{array}$ \\
\hline$g Y_{i, t-1}$ & $\begin{array}{l}-0.0264 \\
(-1.08)\end{array}$ \\
\hline $\mathrm{gSi}_{\mathrm{i}, \mathrm{t}}$ & $\begin{array}{l}0.640^{*+* *+} \\
(7.00)\end{array}$ \\
\hline $\begin{array}{l}\text { Zaman kukla } \\
\text { değişkeni }\end{array}$ & Evet \\
\hline $\mathrm{N}$ & 648 \\
\hline $\operatorname{AR}(1)^{\mathrm{a}}$ & 0.00 \\
\hline $\operatorname{AR}(2)^{b}$ & 0.79 \\
\hline $\begin{array}{l}\text { Hansen J Testc, } \\
\text { p değeri }\end{array}$ & 0.54 \\
\hline $\begin{array}{l}\text { Wald Test }{ }^{\mathrm{d}}, \mathrm{p} \\
\text { değeri }\end{array}$ & 0.00 \\
\hline
\end{tabular}

Not: Değişkenlerin açıklamaları için bknz. Tablo 3 açıklamaları. Parantez içerisindeki değerler, $t$ istatistiklerini ifade etmektedir. a; farkı alınmış hata terimlerinde birinci dereceden otokorelasyonu test etmektedir. b; farkı alınmış hata terimlerinde ikinci dereceden otokorelasyonu test etmektedir. c;modelde aşırı tanımlama hatasını test etmektedir. d;modelin geçerliliğini test etmektedir. ${ }^{*} \mathrm{p}<0.05,{ }^{* *}$ $\mathrm{p}<0.01,{ }^{* * *} \mathrm{p}<0.001$

Tablo 4'te yer alan Fark-GMM modeli sonuçları, Tablo 3'te yer alan model sonuçlarına paralellik arz etmektedir. Hizmetler sektörünün ekonomik büyüme üzerine olan etkisi en yüksek sektör olarak görülürken, sanayi sektörünün ekonomik büyümeye olan katkısının hizmetler sektörüne göre az, tarım sektörüne göre fazla olduğu sonucuna ulaşılmıştır. Modelde yer alan büyümenin bir dönem önceki değeri ya da diğer bir deyişle büyümenin dinamik etkisi ise anlamsız bulunmuştur. Modelde zamana göre birimler arası değişmeyi kontrol etmek amacıyla zaman kukla değişkenleri yer almaktadır. Modelde farkı alınmış hata terimlerinde birinci dereceden otokorelasyon beklendiği gibi görülürken, ikinci dereceden otokorelasyon yer sorunu yer görülmemektedir. Modelde araç değişkenlere ilişkin aşırı tanımlama (over-identification) sorununu test eden Hansen J Testi, modelde bu sorunun yer almadığını göstermektedir. Wald Test sonuçları ise tahmin edilen modelin bir bütün olarak anlamlı olduğunu göstermektedir. Ekonometrik analiz sonucunda elde edilen bulgular, Türkiye'de il bazında büyümeye sektörel olarak en fazla katkının hizmetler sektöründen geldiğini göstermektedir. Hizmetler sektörünü sanayi sektörü izlerken, tarım sektörünün 
ekonomik büyümeye olan katkısının hizmetler ve sanayi sektörünün gerisinde olduğu sonucuna ulaşılmıştır.

\section{Sonuç}

Hizmetler sektörü, Türkiye'de sanayileşmede yaşanan sermaye birikimi ve 1990 sonrasında dünya çapında kazandığı önem ile ön plana çıkmaya başlamıştır. Ancak gelişmekte olan ülkelerde yaşanan hizmetler sektörüne olan hızlı geçiş, geç sanayileşme ve sermaye birikimi sorunundan kaynaklanmaktadır. Türkiye'de tarım sektörünün, ülke ekonomisi içerisindeki payının 1980 yılı sonrasında giderek azaltılması, sanayileşmenin sermaye birikimi sorunu nedeniyle istenilen düzeye gelememesi hizmetler sektörüne olan bir sektörel kaymayı meydana getirmiştir.

Çalışmada İBBS 3.düzey iller düzeyinde ekonomik büyümenin sektörel belirleyicileri test edilmiştir. Elde edilen sonuçlar, ekonomik büyümeyi sırasıyla hizmetler sektörü, sanayi sektörü ve tarım sektörünün desteklediğini göstermektedir. Çalışmada zengin bir düzeyde iller arasındaki farklılıkların dinamik olarak modellendiği GMM modeli sonuçlarında elde edilen bu sonuçlar, ilgili literatüre katkı sağlamaktadır. Bu katkı, büyümenin iller düzeyinde farklıklar hesaba katılarak modellenmesinden kaynaklıdır. Dolayısıyla bu çalışmada heterojen bir veri seti çerçevesinde büyümenin sektörel belirleyicilerinin tespit edilmesi yönündedir. Çalışmanın Türkiye eksenli çalışmalardan farklı olarak bu noktada büyümenin en mikro temeli olan il düzeyine inerek önemli büyüme tespiti yapması, literatüre olan katkısının yanı sıra özgünlüğünü de ifade etmektedir. Çalışmanın elde ettiği bulgular panel veri ekonometrisi analizlerine dayalı olarak hizmetler sektörünün büyümeye olan etkisinin olumlu ve sanayi ve tarım sektörlerine göreli olarak daha fazla olmasıdır. Bu noktada çalışmanın ana hipotezinin doğrulandığ 1 görülmektedir. Çalışmanın ana hipotezinin Türkiye ekonomisinde hizmetler sektörüne olan hızlı geçişin sanayideki sermaye birikimi ve tüketim kalıpları sorunu, hizmetler sektörünün küresel ölçekteki hızlı ilerlemesinin etkisi ve sanayi sektörünün yapısal sorunları gibi faktörler hizmetler sektörünün büyümeye olan etkisinin tarım ve sanayi sektörlerine göre daha fazla olmasına neden olmuştur.

Çalışmanın elde ettiği sonuçlardan politika yapıcılara tavsiye olarak bazı çıkarımlar yapılabilir. Bu çıkarımlardan ilki sermaye ihtiyacı sanayi sektörüne göreli olarak daha az olan hizmetler sektörünün büyümeye olan katkısının yanı sıra verimlilik açısından Türkiye ekonomisinde 'Baumol Hastalığı' na neden olmasının önüne geçilmesi için istihdam, teşvik ve gelişme politikalarının oluşturulmasının gerekliliğidir. Özellikle katma değer oluşturacak yatırımların teşvik edilmesi hizmet sektöründe hem dünya ortalamasını yakalama hem de Baumol Hastalığı'nın önüne geçilmesi anlamında oldukça önemli bir husustur. Çalışmada tarım sektörünün sanayi ve hizmetler sektörünün geride olmasına karşın büyümeyi destekleyen bir sektör olduğu görülmektedir. Tarım sektöründe endüstriyel tarım uygulamaları ile büyümeyi destekleyici ve verimliliği arttırıcı politikalar tercih edilebilir.

Çalışmanın en büyük kısıtı, istatistiksel verilerin 2004 yılı ile 2014 yılları arasında olmasıdır. TÜİK (2018)'den edinilen bilgilerin zaman aralığından kaynaklı veri kısıtı çalışmanın en büyük kısıtlarından birisidir. Gelecek çalışmalara olan öneri ise; bölgesel düzeyde hizmetler ya da diğer sektörleri geliştiren önemli yerel politikaların vaka analizi ya da olay çalışması yöntemleriyle daha derinlemesine büyümenin sektörel belirleyicilerini test etmesidir. 


\section{Kaynakça}

Arellano, M. \& Bond, S. (1991), Some tests of specification for panel data: Monte Carlo evidence and an application to employment equations. Review of Economic Studies, 58 (2), 277-297.

Atiyas, İ. \& Bakış, O. (2015). Structural change and industrial policy in Turkey. Emerging Markets Finance and Trade, 51(6), 1209-1229.

Bairam, E. (1991). Economic growth and Kaldor Law: the case of Turkey: 1925-78., Applied Economics, 23, 1277-1280.

Baltagi, B. H.(2005). Econometric Analysis of Panel Data, Wiltshire: John Wiley \& Sons

Basu, K. \& Maertens, A.(2007). The pattern and causes of economic growth in India. Oxford Review of Economic Policy, 23(2), 143-167.

Chenery, H. B. (1960). Patterns of industrial growth. American Economic Review, 50(4), 624-654.

Chenery, H. B. (1979). Structural change and development policy. New York: Oxford University Press.

Chenery, H. B., Robinson, S. \& Syrquin, M. (1986). Structural transformation. içinde H. B. Chenery, S. Robinson ve M. Syrquin (Ed.). Industrialization and growth: A comparative study içinde (s.11-12). Oxford: Oxford University Press.

Doruk, Ö. T. (2017). Determinants of investment in the manufacturing sector in Turkey. (Doktora tezi, Kadir Has Üniversitesi, İstanbul).

Doruk, Ö. T., Kardaşlar, A. \& Kandır, E.D. (2013). Turkish economy's great transformation: industry, agriculture and economic growth in the process after 1980, A review from the Perspective of Kaldor's first growth law. Empirical Economics Letters, 12(6),587-592.

Dünya Bankası. (2018). Dünya Kalkınma Göstergeleri Veri Taban1,(http://databank.worldbank.org/data/reports.aspx?source=world-developmentindicators), Erişim Tarihi: 28.10.2018

Eichengreen, B. \& Gupta, P. (2011). The service sector as India's road to economic growth. NBER Working Paper no.16757, Cambridge, ABD.

Eser, E. (2011). Türkiye' de uygulanan yatırım teşvik sistemleri ve mevcut sistemin yapısına yönelik öneriler. (DPT Uzmanlık Tezi, Ankara).

Fagerberg J. \& Verspagen, B (1999). Modern capitalism in the 1970s and 1980s, M. Setterfield (Ed.), Growth, employment and inflation içinde (s.113-126), Basingstoke: Palgrave Macmillan.

Hirschman A. O. (1958). The strategy of economic development. New Haven, Conn: Yale University Press.

Kaldor, N.(1966). Causes of the slow rate of growth of the United Kingdom: An inaugural lecture. Cambridge: Cambridge University Press.

Kaldor, N.(1968). Productivity and growth in manufacturing industry: A reply. Economica,35 (140), 385-391

Kefela, G. T. (2010).The Service sector high employment with low productivity growth prospect for emerging economies. Accountancy Business and the Public Interest, 9,125-146.

Kuznets, S. (1966). Modern economic growth. New Haven, CT: Yale University Press. 
Lewis, W. A. (1954). Economic development with unlimited supplies of labour. A.N. Agarwala \& S.P. Singh (Ed.) (1958), The economics of underdevelopment içinde (s. 400-449).Oxford: Oxford University Press.

Myrdal, G. (1957). Economic theory and underdeveloped regions. New York: Harper and Row.

Nurkse, R. (1953). Problems of capital formation in underdeveloped countries. Oxford: Oxford University Press.

Öniş, Z. (2010). Crises and transformations in Turkish political economy. Turkish Policy Quarterly, 9 (3), 45-61.

Palma, G. (2005). Four sources of 'de-industrialization' and a new concept of the 'Dutch disease'. J.A. Ocampo (Ed.), Beyond reforms, structural dynamics and macroeconomic vulnerability içinde (s. 71-116.). Stanford (CA): Stanford University Press.

Pieper, U. (2003). Sectoral regularities of productivity growth in developing countries: A Kaldorian interpretation. Cambridge Journal of Economics, 27 (6), 831-850.

Rosenstein-Rodan, P. (1943). Problems of industrialization of Eastern and South-Eastern Europe. Economic Journal, 53 (210/1), 202-211.

Rowthorn, R. (1995). “Korea at the Cross-roads", CBR Working Paper, no. 11, Cambridge: Centre for Business Research, University of Cambridge.

Rowthorn, R. ve Coutts, K. (2004). Deindustrialization and the balance of payments in advanced economies. Cambridge Journal of Economics, 28 (5),767-790.

Rowthorn, R. \& Wells, J.R. (1987). De-industrialization and foreign trade. Cambridge, Cambridge University Press.

Rybczynski, T. M. (1955). Factor endowments and relative commodity prices. Economica, 22, 336-341.

Strateji Ve Bütçe Başkanlığ1.(2018). Ekonomik ve Sosyal Göstergeler (http://www.sbb.gov.tr/ekonomik-ve-sosyal-gostergeler/), Erişim Tarihi:24.10.2018.

Szirmai, A. (2012). Industrialization as an engine of growth in developing countries, 1950-2005. Structural Change and Economic Dynamics, 23 (4), 406-20.

Szirmai, A. \& Verspagen, B. (2011). Manufacturing and economic growth in developing countries, 1950-2005. UNU-MERIT Working Paper Series, no. 2011-069, Maastricht: United Nations University, Maastricht Economic and Social Research Institute on Innovation and Technology.

Soubbotina,T. P.(2004). Beyond economic growth an introduction to sustainable economic growth. Washington: World Bank WBI Learning Source Series.

TÜIKK (2018) Bölgesel İstatistikler (https://biruni.tuik.gov.tr/medas/?kn=116\&locale=tr), Erişim Tarihi: 28.10.2018

Yamak, R. \& Sivri, U. (1997). Ekonomik büyüme ve Kaldor Yasası: Türkiye örneği 1979-1994. İktisat, İsletme ve Finans, 12 (139), 9-21. 